\title{
Analysis on Production Efficiency of Laying Hens in China—Based on the Survey Data of Five Provinces
}

\author{
Wu Yuhuan ${ }^{1} \&$ Qin $\mathrm{Fu}^{1}$ \\ ${ }^{1}$ Institute of Agricultural Economics and Development, Chinese Academy of Agricultural Sciences, Beijing, \\ China \\ Correspondence: Qin Fu, Institute of Agricultural Economics and Development, Chinese Academy of \\ Agricultural Sciences, Beijing, No.12 South Zhongguancun Street, China. Tel: 86-010-8210-9780. E-mail: \\ qinfu@caas.cn
}

Received: March 14, 2019

Accepted: April 23, 2019 Online Published: June 31, 2019

doi:10.5539/jas.v11n8p280

URL: https://doi.org/10.5539/jas.v11n8p280

This research is financed by National Key R\&D Program of China (2018YFD0501305), Modern Agricultural Industrial Technology System Project (CARS-40-K28).

\begin{abstract}
Problem Description: China is one of the major countries in the world of laying hens. However, compared with the United States and the European Union, the production efficiency of laying hens in China still lags far behind. Objectives: To guide the farmers to improve the effiency of laying hens breeding, we use the survey data to analysis the effiency and give advice. Methodology: This paper uses field survey data from five provinces to measure the technical efficiency of laying hens through DEA model. Key Findings: The results show that the average technical efficiency of survey households is $95.411 \%$. Through the analysis, we found that layer chicken production technology in Hebei province is the highest, Liaoning province layer chicken production efficiency is the lowest. Implications: In the overall layout of laying hens breeding, the laying hens industry development should vigorously promote the rationalization of regional layout, give full play to regional advantages, and promote the development of laying hens industry.
\end{abstract}

Keywords: laying hens breeding, factor input, breeding efficiency

\section{Introduction}

Judging from the number of laying hens, since 1978, the industrial structure of laying hens in China has been constantly optimized, with gradually formed industrial advantages and enhanced industrial competitiveness. According to FAO statistics, the number of laying hens in China increased from 1.931 billion to 3.12 billion from 2000 to 2018, with an increase of $61.58 \%$. The number of laying hens in the world increased from 4.973 billion to 7.891 billion, with an increase of $58.67 \%$. According to calculations by FAO data, in 2018, the global number of laying hens is about 7.891 billion, and the number of laying hens in China is about 3.12 billion, accounting for $39.53 \%$ of the world's total (Table 1). The production of egg in China can meet the demand of the domestic egg market due to the support of progenitor generation, parent generation and commodity generation of laying hens. 
Table 1. Number of laying hens in China and the world (Units: $10^{3}$ )

\begin{tabular}{llll}
\hline Year & Laying hens in China & Laying hens in the world & The proportion \\
\hline 2000 & 1930728 & 4973197 & $38.82 \%$ \\
2001 & 1960030 & 5104308 & $38.40 \%$ \\
2002 & 2032233 & 5268888 & $38.57 \%$ \\
2003 & 2035608 & 5362179 & $37.96 \%$ \\
2004 & 2135187 & 5557018 & $38.42 \%$ \\
2005 & 2234630 & 5722925 & $39.05 \%$ \\
2006 & 2305184 & 5919076 & $38.94 \%$ \\
2007 & 2386209 & 6077851 & $39.26 \%$ \\
2008 & 2487063 & 6254151 & $39.77 \%$ \\
2009 & 2536580 & 6348748 & $39.95 \%$ \\
2010 & 2563295 & 6520825 & $39.31 \%$ \\
2011 & 2581398 & 6616415 & $39.02 \%$ \\
2012 & 2656831 & 6821009 & $38.95 \%$ \\
2013 & 2686888 & 6946665 & $38.68 \%$ \\
2014 & 2737784 & 7113998 & $38.48 \%$ \\
2015 & 2978377 & 7525802 & $39.58 \%$ \\
2016 & 3014565 & 7671156 & $39.30 \%$ \\
2017 & 3153819 & 7838380 & $40.24 \%$ \\
$2018 *$ & 3119705 & 7891167 & $39.53 \%$ \\
\hline
\end{tabular}

Note. 2018 data is estimated.

Source: FAO.

In terms of the production of egg, egg is the most important bird egg variety in China, and the production of egg accounts for more than $80 \%$ of the production of bird egg. Therefore, we can analyze the production of egg through the change of the production of bird egg. China's egg production continued to grow from 2000 to 2018 , according to the FAO data. In 2000, China's egg production was 18.91 million tons. According to calculations, China's egg production in 2018 was 30.39 million tons, an increase of 60.7 percent over 2000. China's egg production accounted for between $36 \%$ and $41 \%$ of the world's egg production, of which the largest proportion was $40.49 \%$ in 2016 . From the perspective of the overall trend, the proportion shows a slight upward trend (as shown in table 2).

Table 2. Production of egg in China and the world (Units: $t$ )

\begin{tabular}{llll}
\hline Year & Egg production in China & Egg production in the world & The proportion \\
\hline 2000 & 18911899 & 51139609 & $36.98 \%$ \\
2001 & 19153719 & 52184057 & $36.70 \%$ \\
2002 & 19658920 & 53493695 & $36.75 \%$ \\
2003 & 20183020 & 54312163 & $37.16 \%$ \\
2004 & 20500750 & 55562956 & $36.90 \%$ \\
2005 & 21040577 & 56686312 & $37.12 \%$ \\
2006 & 20935240 & 57945805 & $36.13 \%$ \\
2007 & 21833160 & 59585101 & $36.64 \%$ \\
2008 & 23292120 & 61735079 & $37.73 \%$ \\
2009 & 23633516 & 62937724 & $37.55 \%$ \\
2010 & 23820080 & 64240171 & $37.08 \%$ \\
2011 & 24231630 & 65497298 & $37.00 \%$ \\
2012 & 24659155 & 67096642 & $36.75 \%$ \\
2013 & 24786994 & 68690640 & $36.08 \%$ \\
2014 & 24942678 & 70114454 & $35.57 \%$ \\
2015 & 30809783 & 76678893 & $40.18 \%$ \\
2016 & 31972681 & 78968196 & $40.49 \%$ \\
2017 & 31338856 & 80088559 & $39.13 \%$ \\
$2018 *$ & 30390957 & 78978746 & $38.48 \%$ \\
\hline
\end{tabular}

Note. 2018 data is estimated.

Source: FAO. 
From the perspective of geographical distribution, the northern region is the main production area of China's egg production, and the four regions of Shandong, Hebei, Henan and Liaoning account for about half of the country's egg production. Jiangsu, Hubei, Sichuan, Anhui bird egg production is bigger in southern area. From 2010 to 2018, the output of bird egg in the northern region has always occupied a large share, with Shandong, Hebei and Henan showing a declining trend. There is an upward trend in Liaoning. However, the 4 southern provinces showed little change. Since 2006, they also showed a downward trend, but the decline was smaller than that in the north (as shown in Table 3). With the development of breeding technology and equipment, the trend of laying hens southward is obvious. Because of the environmental protection policy control and the land use restraint and so on the condition, the laying chicken culture also presents the westward trend.

Table 3. Major egg-producing provinces in China (Unit: 10,000 tons)

\begin{tabular}{lllllllll}
\hline Year & Hebei & Shandong & Henan & Liaoning & Jiangsu & Hubei & Sichuan & Anhui \\
\hline 2010 & 339.08 & 384.28 & 388.59 & 275.73 & 190.57 & 132.59 & 144.39 & 119.02 \\
2011 & 339.84 & 401.19 & 390.5 & 277.4 & 194.86 & 137.03 & 144.85 & 119.65 \\
2012 & 342.56 & 401.99 & 404.17 & 279.9 & 197.2 & 139.36 & 146.44 & 122.65 \\
2013 & 346.06 & 396.21 & 410.23 & 276.82 & 197.87 & 145.05 & 145.2 & 124.53 \\
2014 & 362.71 & 388.02 & 404 & 279.3 & 194.58 & 155.06 & 145.35 & 122.53 \\
2015 & 373.59 & 423.9 & 410 & 276.5 & 196.23 & 165.29 & 146.65 & 134.66 \\
2016 & 388.54 & 440.59 & 422.5 & 287.6 & 198.5 & 167.77 & 148.12 & 139.55 \\
2017 & 383.72 & 444.78 & 401.18 & 270.43 & 183.39 & 168.17 & 144.5 & 154.7 \\
$2018 *$ & 395.18 & 445.36 & 412.94 & 280.38 & 196.07 & 150.4 & 145.65 & 129.59 \\
\hline
\end{tabular}

Note. 2018 data is estimated.

Source: National Bureau of Statistics.

\section{Data Source and Descriptive Statistical Analysis}

\subsection{Data Sources}

According to the project requirements of the national modern agricultural industrial technology system project, the data required in this paper are all from the field research from September 2018 to April 2019. The questionnaire mainly includes family basic information, basic information of layer breeding, factor investment, income from layer breeding and social services of layer breeding. The research method is mainly in the form of a face-to-face interview, in which the investigator communicates directly with the farmers to reflect the farmers' actual situation to the greatest extent. Hebei, Hubei, Jiangsu, Liaoning and Sichuan were selected in the survey area. Among them, 93 households in Hebei, 100 in Hubei, 122 in Jiangsu and 99 in Liaoning were selected. The five selected provinces involved east, central and west, which were highly representative. 
Table 4. Regional distribution of large-scale breeding of laying hens

\begin{tabular}{|c|c|c|c|c|c|c|}
\hline Province & City & Country & Frequency & The percentage & Frequency & The percentage \\
\hline \multirow{3}{*}{ Hebei } & \multirow{2}{*}{ Shijiazhuang } & Jinzhou & 22 & 4.2 & \multirow{3}{*}{93} & \multirow{3}{*}{17.6} \\
\hline & & Zhao country & 6 & 1.1 & & \\
\hline & Handan & Guantao & 65 & 12.3 & & \\
\hline \multirow{6}{*}{ Hubei } & Wuhan & Huangpi & 11 & 2.1 & \multirow{6}{*}{100} & \multirow{6}{*}{18.9} \\
\hline & Xiantao & Xiantao & 25 & 4.7 & & \\
\hline & Xiaogan & Hanland & 16 & 3 & & \\
\hline & \multirow{2}{*}{ Huanggang } & XiShui & 8 & 1.5 & & \\
\hline & & YingShan & 17 & 3.2 & & \\
\hline & Ezhou & Liangzi lake & 23 & 4.3 & & \\
\hline \multirow{3}{*}{ Jiangsu } & \multirow{3}{*}{ Nantong } & Haian & 41 & 7.8 & \multirow{3}{*}{122} & \multirow{3}{*}{23.1} \\
\hline & & Rudong & 41 & 7.8 & & \\
\hline & & Rugao & 40 & 7.6 & & \\
\hline \multirow{6}{*}{ Liaoning } & \multirow{4}{*}{ Chaoyang } & Beipiao & 6 & 1.1 & \multirow{6}{*}{99} & \multirow{6}{*}{18.7} \\
\hline & & Kazuo & 13 & 2.5 & & \\
\hline & & Kangping & 14 & 2.6 & & \\
\hline & & Longcheng & 37 & 7 & & \\
\hline & \multirow{2}{*}{ Huludao } & lianshan & 14 & 2.6 & & \\
\hline & & Nanpiao & 15 & 2.8 & & \\
\hline \multirow{7}{*}{ Sichuan } & Chengdu & Jintang & 25 & 4.7 & \multirow{7}{*}{115} & \multirow{7}{*}{21.7} \\
\hline & \multirow{4}{*}{ Deyang } & Jingyang & 3 & 0.6 & & \\
\hline & & Luojiang & 2 & 0.4 & & \\
\hline & & Mianzhu & 25 & 4.7 & & \\
\hline & & Zhongjiang & 3 & 0.6 & & \\
\hline & \multirow{2}{*}{ Mianyang } & Anxian & 31 & 5.9 & & \\
\hline & & Fucheng & 26 & 4.9 & & \\
\hline Total & & & 529 & 100 & 529 & 100 \\
\hline
\end{tabular}

Source: Field research.

\subsection{Survey Household Factor Input}

From Table 5 statistical analysis we can see, every one hundred only labor costs in addition to the scale of farming in 800 yuan of above, we here in the artificial cost refers to the farmers the opportunity cost of laying hens breeding, land costs for land rent and land use of the opportunity cost of one hundred per material and service refers to the daily investment, fixed assets depreciation and cope with the environmental policy. Since there was only one farmer from 300 to 1999 , we mainly analyzed the factor input rules of farmers from 2000 to above. As can be seen from the above table, the larger the scale of breeding, the lower the labor cost per hundred. This is because farmers with larger scale of breeding adopt more mechanized breeding, which replaces artificial breeding and reduces labor input. The cost per hundred pieces of land is about 60 yuan, among which, the land area above 50000 is more than 2000-9999 and 10000-49999 pieces because more functional land is needed. Material and service charges may be related to depreciation and increased expenditure in response to environmental policies.

Table 5. Basic information of household farming scale

\begin{tabular}{llllll}
\hline The size of the laying hens & Number & The percentage & Labor cost per hundred & Land cost per hundred & Material and service charge per hundred \\
\hline $300-1999$ & 1 & 0.2 & 405.5555556 & 66.66666667 & 16731.11111 \\
$2000-9999$ & 229 & 43.3 & 860.0738935 & 59.78803767 & 18268.02403 \\
$10000-49999$ & 261 & 49.3 & 858.2992723 & 59.74258312 & 18272.97075 \\
50000 or more & 38 & 7.2 & 822.9373787 & 63.26942988 & 18796.44475 \\
\hline
\end{tabular}




\section{Production Efficiency Analysis of Farmers}

\subsection{Theoretical Model}

We assume that the basic form of the production function is:

$$
y_{i}=f\left(x_{i}, \beta\right) \cdot \xi_{i}
$$

where, $\beta$ is the parameter to be estimated, $\xi_{i}$ is the production level to make the product reach the frontier of efficiency, and $0<\xi_{i} \leq 1$. Considering that the production function is also subject to random shocks, the basic form of the production function is:

$$
y_{i}=f\left(x_{i}, \beta\right) \cdot \xi_{i} e^{v_{i}}
$$

where, $e^{v i}$ is random shock, $e^{v i}>0$. The frontier of production function $f\left(x_{i}, \beta\right) \cdot e^{v_{i}}$ is random, so this kind of model is called the "stochastic frontier model". The stochastic frontier model was proposed by Aigner, Lovell, and Schmidt (1977) and has been widely used in the empirical field.

$$
\ln y_{i}=\beta_{0}+\sum_{k=1}^{K} \beta_{k} \ln x_{k i}+\ln \xi_{i}+v_{i}
$$

Based on the Cobb-Douglas production function and assuming the production function $f\left(x_{i}, \beta\right)=e^{\beta_{0}} x_{1 i}^{\beta_{1}} \ldots x_{k i}^{\beta_{k}}$, the deformation of the production function can be obtained as follows:

$$
\ln y_{i}=\beta_{0}+\sum_{k=1}^{K} \beta_{k} \ln x_{k i}+v_{i}-u_{i}
$$

As a result of $0<\xi_{i} \leq 1, \ln \xi_{i} \leq 0$, let $u_{i}=-\ln \xi_{i} \geq 0$.

where, $u_{i} \geq 0$ is the item of "inefficiency", reflecting the distance between the manufacturer $i$ and the efficiency frontier.We use the semi-normal distribution to estimate the inefficiencies. The technical efficiency can be calculated by calculating the ratio of the observed output to the corresponding random frontier output, that is:

\subsection{Empirical Analysis}

$$
T E=\frac{y_{i}}{\exp \left(x_{i}+v_{i}\right)}=\frac{\exp \left(x_{i} \beta+v_{i}-u_{i}\right)}{\exp \left(x_{i} \beta+v_{i}\right)}=\exp \left(-u_{i}\right)
$$

We select the number of laying hens as the output, capital, labor and land area as the input, and build the following model based on the Cobb-Douglas function:

$$
\ln Y=\beta_{0}+\beta_{1} \ln (\text { labor })+\beta_{2} \ln (\text { cap })+\beta_{3} \ln (\text { land })+v_{i}-u_{i}
$$

where, $Y$ represents survey 2018 households laying hens breeding stock, labor represents laying hens breeding labour recruitment days (including family labor force and number of employees), cap means money of laying hens breeding(including laying hens breeding daily devotion, depreciation of fixed assets and to cope with the environmental policy and increase cost), land means area of farm.

\subsection{Results}

We used frontier 4.1 to estimate the farmers' technical efficiency. The estimated results show that the average technical efficiency of survey households is $95.411 \%$, that of survey households in Hebei province is $96.34 \%$, that of survey households in Hubei province is $95.75 \%$, that of survey households in Jiangsu province is $95.14 \%$, that of Liaoning province is $94.98 \%$, and that of Sichuan province is $95.01 \%$. Through the above analysis, we found that the laying chicken production technology in Hebei province is the highest, and the reasons are as follows:

Laying hens in Hebei province have a long history. The development of laying hens in Hebei province started early with a large number of laying hens. For many years, laying hens' inventory and egg output ranked top three in China. Farmers have high breeding technology and pay attention to breeding management. Water quality monitoring, drug sensitivity test, antibody detection and disinfection effect evaluation are widely used. The detection frequency and density are very high. The disease and death of laying hens were less in the process of breeding. We will take appropriate measures to prevent and control epidemics.

The farming efficiency of Jiangsu, Sichuan and Hubei provinces is lower than that of Hebei province, but the development trend is good. At present, the development of laying hens industry in China shows a trend of equalization. Compared with the north, the southern layer breeding industry started late, but the breeding scale is higher, the equipment is advanced, the management level and the enterprise's operating conditions are relatively good. 


\section{Conclusions and Suggestions}

\subsection{Conclusion}

The average technical efficiency of survey households was $95.411 \%$. Through the above analysis, we found that Hebei province layer breeding production technology is the highest; the efficiency of layer breeding is the lowest in Liaoning province, which is related to the input of local land factors. Northern area has endowment advantage and comprehensive comparative advantage in breeding laying hens compared with other areas in China, so in short term laying hens breeding layout in China will be mainly in the north, especially in north China. South area in China should vigorously develop and utilize and upgrade the existing resources, promote the regional moderate scale cultivation of laying hens.

\subsection{Suggest}

\subsubsection{Mechanized and Standardized Production}

Farmers need to improve the level of chicken coop construction, improve technology, feed and so on, improve the ability to deal with the risk of large-scale farming. In 2017, the price of egg appeared a "roller coaster" situation, and the farmers failed to cope with the situation and their income was showing an obvious decline, forcing some farmers with anti-risk ability to withdraw from the laying hens breeding market. At the same time, the government formulated various environmental policies, farmers environmental pressure is increasing. However, the environmental protection requirements vary from place to place. Jiangsu, Zhejiang, Fujian, Hubei, Shandong and other places have higher environmental protection requirements and stronger implementation for the breeding industry.

\subsubsection{Make Full Use of Agricultural Credit}

One of the important characteristics of modern agricultural development is the use of advanced production equipment and technology, and the use of advanced equipment and technology cannot be separated from the support of funds. In addition, compared with planting, the breeding industry invests needs more money in fixed assets and equipment, which requires more agricultural credit funds. Agricultural credit funds can enable farmers to obtain the investment needed for breeding relatively quickly. Meanwhile, advanced technologies and equipment can be adopted to reduce the cost of breeding, improve the efficiency of breeding and obtain excess profits.

\subsubsection{Use Modern Information Technology to Master Market Information}

Layer farmer can make full use of network sale, fixed customer group, undertake egg sale directly. At the same time, through the combination of retail and online sales, improve the overall profitability of the chicken farm. And attract the ability to egg business into shares, joint in-depth marketing efforts. At the same time, e-commerce can reduce the information asymmetry between supply and demand in the process of product production, develop order agriculture, and directly connect the production and demand of agricultural products.

\subsubsection{Improve Breeding Technology}

First, advances in aquaculture technology can address the impact of environmental policies. Because of the traditional aquaculture equipment, sewage treatment and sanitary conditions are relatively poor. The application of professional equipment and the progress of breeding technology can greatly improve the sanitary conditions and sewage treatment capacity. The improvement of aquaculture technology will become a necessary condition for the development of large-scale aquaculture in the future.

Secondly, breeding technology is directly related to breeding efficiency. Feed cost occupies bigger share in cost of layer chicken breed. Reducing cost is an important way to improve the income of laying hens. Through technological progress, the cost of laying hens can be reduced and the income of laying hens can be increased. The content of other nutrients can be regulated in proportion to feeding standards through technological advances. Scientific breeding should be widely used which means a technology assure the nutrition according to the quantity laying hens need. Finally, green feed can be made through technological progress to ensure feed safety.

\section{References}

Demırcan, V., Yılmaz, H., Dernek, Z., Bal, T., Gül, M., \& Koknaroglu, H. (2010). Economic analysis of different laying hen farm capacities in turkey. Agricultural Economics, 56(10), 489-497. https://doi.org/10.1111/ j.1574-0862.2009.00427.x 
Dong, X. Y., Yang, C. F., Tang, S. Q., Jiang, Q. Y., \& Zou, X. T. (2010). Effect and mechanism of glutamine on productive performance and egg quality of laying hens. Asian Australasian Journal of Animal Sciences, 23(8), 1049-1056. https://doi.org/10.5713/ajas.2010.90611

Hegelund, L., Rensen, J. T., \& Hermansen, J. E. (2006). Welfare and productivity of laying hens in commercial organic egg production systems in denmark. NJAS Wageningen Journal of Life Sciences, 54(2), 147-155. https://doi.org/10.1016/S1573-5214(06)80018-7

Lambton, S., Knowles, T., Yorke, C., \& Nicol, C. (2015). The risk factors affecting the development of vent pecking and cannibalism in free-range and organic laying hens. Animal Welfare, 24(1), 101-111. https://doi.org/10.7120/09627286.24.1.101

Li, Z. M. (2010). The short-term market price transmission mechanism of egg industry chain in china. Scientia Agricultura Sinica, 43(23), 4951-4962. https://doi.org/10.1097/MOP.0b013e3283423f35

Mench, J. A., Sumner, D. A., \& Rosenmolina, J. T. (2011). Sustainability of egg production in the united states--the policy and market context. Poult Sci, 90(1), 229-240. https://doi.org/10.3382/ps.2010-00844

Sun, X. H., Sun, S., Li, C. L., \& Zhang, G. T. (2011). Seasonal and spatial variability in egg production, abundance and production of small copepods in and near jiaozhou bay, China. Journal of Plankton Research, 33(5), https://doi.org/741-750.10.1093/plankt/fbq135

Williams, T. D. (2005). Mechanisms underlying the costs of egg production. Bioscience, 55(1), 39-48. https://doi.org/10.1641/0006-3568(2005)055[0039:MUTCOE]2.0.CO;2

Windhorst, H.-W. (2008). Asian changing role in the global egg industry-An analysis of past, present and foreseeable future dynamics. World's Poultry Science Journal, 64(04), 533. https://doi.org/10.1017/ S0043933908000196

Yang, H. (2013). Livestock development in China: Animal production, consumption and genetic resources. Journal of Animal Breeding and Genetics, 130(4). https://doi.org/249.10.1111/jbg.12045

Yang, N., Nys, Y., Bain, M., \& Immerseel, F. V. (2011). Social economic aspects of egg production in China. Improving the Safety \& Quality of Eggs \& Egg Products, 32(2), 17-26. https://doi.org/10.1533/ 9780857093912.1.17

\section{Copyrights}

Copyright for this article is retained by the author(s), with first publication rights granted to the journal.

This is an open-access article distributed under the terms and conditions of the Creative Commons Attribution license (http://creativecommons.org/licenses/by/4.0/). 